\title{
Anger, Hostility, and Hospitalizations in Patients with Heart Failure
}

\author{
Felicia Keith ${ }^{1}$, David S. Krantz ${ }^{1}$, Rusan Chen $^{2}$, Kristie M. Harris ${ }^{4}$, Catherine M. Ware ${ }^{1}$, Amy \\ K. Lee ${ }^{1}$, Paula G. Bellini ${ }^{1}$, and Stephen S. Gottlieb ${ }^{3}$ \\ ${ }^{1}$ Department of Medical and Clinical Psychology, Uniformed Services University of the Health \\ Sciences, Bethesda, MD \\ ${ }^{2}$ Center for New Designs in Learning and Scholarship, Georgetown University, Washington, DC \\ ${ }^{3}$ Department of Medicine, Division of Cardiology, University of Maryland School of Medicine, \\ Baltimore, MD \\ ${ }^{4}$ Department of Psychology, The Ohio State University, Columbus, $\mathrm{OH}$
}

\begin{abstract}
Objective-Heart failure patients have a high hospitalization rate, and anger and hostility are associated with coronary heart disease morbidity and mortality. Using structural equation modeling, this prospective study assessed the predictive validity of anger and hostility traits for cardiovascular and all-cause re-hospitalizations in patients with heart failure.
\end{abstract}

Methods-146 heart failure patients were administered the STAXI and Cook-Medley Hostility Inventory to measure anger, hostility, and their component traits. Hospitalizations were recorded for up to 3 years following baseline. Causes of hospitalizations were categorized as heart failure, total cardiac, non-cardiac, and all-cause (sum of cardiac and non-cardiac).

Results-Measurement models were separately fit for Anger and Hostility, followed by a Confirmatory Factor Analysis to estimate the relationship between the Anger and Hostility constructs. An Anger model consisted of State Anger, Trait Anger, Anger Expression Out, and Anger Expression In, and a Hostility model included Cynicism, Hostile Affect, Aggressive Responding, and Hostile Attribution. The latent construct of Anger did not predict any of the hospitalization outcomes, but Hostility significantly predicted all-cause hospitalizations. Analyses of individual trait components of each of the two models indicated that Anger Expression Out predicted all-cause and non-cardiac hospitalizations, and Trait Anger predicted non-cardiac hospitalizations. None of the individual components of Hostility were related to re-hospitalizations or death.

Conclusion-The construct of Hostility and several components of Anger are predictive of hospitalizations that were not specific to cardiac causes. Mechanisms common to a variety of health problems, such as self-care and risky health behaviors, may be involved in these associations.

*Address for correspondence: David S. Krantz, Ph.D., (david.krantz@usuhs.edu). Department of Medical and Clinical Psychology, Uniformed Services University of the Health Sciences, 4301 Jones Bridge Rd., Bethesda MD, 20814. 


\section{Keywords}

anger; hostility; heart failure; hospitalizations

\section{Introduction}

Heart failure (HF), the inability of the heart to pump sufficient blood to supply the body's needs without an increase in cardiac pressures, is a chronic disorder affecting over 5.8 million individuals in the United States (Levy et al., 2002; Lloyd-Jones et al., 2010). It is a major burden to the health care system, costing over 39 billion dollars in health care, medications, and lost productivity each year (Dunlay et al., 2011; National Center for Chronic Disease Prevention and Health Promotion, 2010). Despite efforts to reduce readmissions, $\mathrm{HF}$ is still one of the largest contributors to re-hospitalization, with rates estimated at 30\% for the 60-90 days post discharge (Jencks, Williams, \& Coleman, 2009). Numerous comorbidities are associated with HF (e.g., renal disorders, pulmonary disease, etc.), and many hospitalizations directly result from these comorbidities, rather than HF alone (Alharethi, Rasmusson, Budge, Benuzillo, \& Kfoury, 2013; Krumholz, 2013). Therefore, it is important to identify potentially modifiable causes of re-hospitalization in HF patients.

Among patients with coronary artery disease, traits such as hostility and anger have also been implicated as risk factors for poor outcomes (Gabbay et al., 1996; Krantz et al., 2006; Suls \& Bunde, 2005). The Cook-Medley Hostility Inventory (Cook \& Medley, 1954) is predictive of all-cause mortality, as well as mortality as a result of coronary artery disease (Wong, Sin, \& Whooley, 2014; Barefoot, Dodge, Peterson, Dahlstrom, \& Williams, 1989; Wong, Na, Regan, \& Whooley, 2013). This measure of Hostility consists of attitudes including cynicism, hostile attributions, and hostile-affect (Costa, Zonderman, McCrae, \& Williams, 1986; Barefoot et al., 1989). The emotional state of anger is often measured in terms directionality (in versus out) and chronicity (e.g., state vs. trait) (Spielberger, Jacobs, Russell, \& Crane, 1983). Anger outbursts can also trigger acute cardiac events, such as myocardial infarction (Buckley et al., 2015; Mittleman et al., 1995), and the effects of anger and hostility appear to be strongest in populations previously diagnosed with coronary heart disease (Chida \& Steptoe, 2009). Although these constructs are related, some investigators have suggested that examining hostility and anger separately may be productive (Denollet \& Pederson, 2009).

In patients with $\mathrm{HF}$, there is evidence that anger and hostility predict morbidity and mortality (Angerer et al., 2000; Chaput et al., 2002). The primary focus of existing research has been on cardiovascular events (MI, cardiac procedures, death, etc.) in HF patients and not necessarily on hospitalizations alone (Kop, Synowski, \& Gottlieb, 2011b; Rutledge, Reis, Linke, Greenberg, \& Millis, 2006). With respect to incident HF, traits related to "anger proneness" predict HF events, with the latter determined, in part, by HF hospitalizations (Kucharska-Newton et al., 2014).

Although there is evidence that many hospitalizations in HF patients result from comorbidities of HF and/or cardiovascular disease (Jencks et al., 2009; Krumholz, 2013), 
little is known about hostility and anger in relation to cardiac-related and all-cause hospitalizations in these individuals. These hospitalizations may result not only from pathophysiologic changes directly associated with worsening of disease (Miller, Freedland, Carney, Stetler, \& Banks, 2003; Krantz et al., 2011), but also indirectly via behavioral factors such as reduced medication and diet compliance, and other health-impairing behaviors (Black, Zimmerman, \& Coryell, 1999; McDermott, Schmitt, \& Wallner, 1997; Schwebel et al., 2006; Smith \& Frohm, 1985). Since a high percentage of re-hospitalizations in HF patients are from causes other than primary HF or cardiac diagnosis (Jencks et al., 2009; Krumholz, 2013), it is important to also examine hospitalizations for a range of causes in HF patients. With respect to anger, at least one study Jenner, Strodl, and Schweitzer (2009) demonstrated that trait anger predicted length of all-cause hospital stay, but not hospital readmissions in HF patients. This study did not differentiate between causes of hospitalizations.

The purpose of the present study is to determine the relationships of hostility, anger, and their subcomponents to hospitalizations in patients with HF. We used structural equation modeling to determine the prospective relationship of the constructs of anger and hostility to hospitalizations in HF patients over a follow-up period of 36 months. Relationships with allcause hospitalizations as well as hospitalizations for HF or cardiac causes were examined. We hypothesized that the latent constructs of anger and hostility would significantly contribute to cardiac and HF hospitalizations. Since hostility may predict total and not just cardiovascular mortality (Barefoot, Dahlstrom, \& Williams, 1983), we hypothesized that hostility might be additionally related to hospitalizations for all causes, including noncardiac readmissions.

\section{Methods}

\section{Study participants}

A total of 146 participants were enrolled in the longitudinal Behavioral Triggers in Heart Failure (BETRHEART) study (Endrighi et al., 2016), designed to examine psychological predictors of hospitalizations and death in patients with HF. As a part of this study, patients completed baseline testing session and a second assessment 3 months later. Inclusion criteria included: left ventricular ejection fraction (LVEF) $\leq 40 \%$ as assessed by echocardiography, age $\geq 18$ years, and symptomatic HF (NYHA class II-IV) for $\geq 3$ months. Exclusion criteria were: recent myocarditis, valve disease or thyroid dysfunction as primary HF etiology, current alcohol abuse, left ventricular assist device, prior heart transplantation, active cancer treatment, and severe cognitive impairment. Lost to follow-up was defined as unable to contact the participant by phone, mail, or in-person for a 1 year period. Forty-four patients who could not be contacted had available medical records, and their hospitalization data were included in the study. Sixteen patients withdrew from the study, but their hospitalization data were also used with their permission up until the time of their withdrawal. Thirty-two participants died during the duration of the study; hospitalization records were recorded until death occurred. 


\section{Procedures}

As part of the larger BETRHEART study examining behavioral triggers in HF, patients completed baseline assessments of anger and hostility and provided a detailed medical history. Patients were then contacted via telephone at 6-month intervals over the following 3 years. If the participant had died, their next of kin or spouse was interviewed for cause and date of death. Appropriate Institutional Review Boards at both the Uniformed Services University and University of Maryland Medical Center approved this study.

\section{Study Measures}

State Trait Anger Expression Inventory, Second Edition (STAXI-II)-The STAXIII is a 57-item instrument measuring anger and its subcomponents. It consists of 6 anger scales: State Anger, Trait Anger, Anger Expression In, Anger Expression Out, Anger Control Out, and Anger Control In (Spielberger, 1999). Items are coded on a 4-point Likert scale (ranging from "almost never", "sometimes", "often", and "almost always"). Questions that assess state-anger include prompts such as: "I am furious" and "I feel irritated". When assessing for trait-anger participants are asked questions such as: "I am quick tempered" and "I have a fiery temper". The STAXI has been found to be both internally reliable (Cronbach's alpha ranging from .79 to .88), and valid (Etzler, Rohrmann, \& Brandt, 2014). Scoring of all participant responses and inventory subscales were done according to manual instructions (Spielberger, 1999).

Cook-Medley Hostility Scale-The Cook-Medley Hostility Scale is a 50 item instrument designed to measure hostility (Cook \& Medley, 1954). Barefoot et al., (1989) suggests that the Hostility Scale is comprised of six subscales: Cynical Hostility, Hostile Attributions, Hostile Affect, Social Avoidance, Aggressive Responding and Other. Each question is answered as a dichotomous true or false. Examples of questions included on each scale are as follows: Cynical Hostility Scale: "I have often had to take orders from someone who did not know as much as I did"; Hostile Attribution: "someone has it in for me", Hostile Affect "some of my family have habits that bother me and annoy me very much", Aggressive Responding: "I don't blame anyone for trying to grab everything he can get in this world", Social Avoidance: "I am likely not to speak to people until they speak to me", and Other: "I am against giving money to beggars". The measure has shown to have both convergent and discriminant validity and reliability (Smith \& Frohm, 1985). Responses were scored and subscales scores were created based on the inventory manual (Cook \& Medley, 1954).

Additional study measures-The larger BETRHEART study also included measures of other lifestyle and psychosocial variables such as social support, depression, and variables related to health and self-care behaviors (e.g., dietary, weight, medication adherence, exercise; Riegel, Carlson, Moser, Sebern \& Hicks, 2004) and attitudes (e.g., optimism, selfefficacy). Several of these variables involved standardized measures (e.g., social support, Cohen \& Wills, 1985; severity of HF symptoms, Green, 2000) and other variables were assessed using ad hoc measures of self-care. Analysis of these variables and their complex relationship to study outcomes is beyond the scope of this report. 
Hospitalization endpoints-Hospitalizations were recorded during the 3-month initial study period and at subsequent 6-month telephone interviews for up to 36-months. Hospitalizations prior to death were used in the case of participants who died. Death from any cause was also measured based on next of kin reports and hospitalization records, and verified with the Social Security Death Index. Hospitalizations and their cause were selfreported by participants and subsequently verified by medical record review.

Hospitalizations were categorized into four overlapping categories: HF related hospitalizations ( $\mathrm{n}=183$ ), cardiac related hospitalizations (which included HF related hospitalizations, $n=291$ ), hospitalizations for non-cardiac reasons (e.g., non-cardiac surgeries, acute illness, injuries, $\mathrm{n}=284$ ), and all-cause hospitalizations (included both cardiac and non-cardiac hospitalizations, $\mathrm{n}=575$ ). HF hospitalizations included those due to pump failure or fluid overload. Cardiac related hospitalizations included these HF hospitalizations, but also hospitalizations for reasons such as myocardial infarction, angina, myocardial ischemia, and also for cardiac revascularization procedures. Non-cardiac hospitalizations included any other hospitalizations for any non-cardiac reason. All-cause hospitalization was a composite variable containing all three types of hospitalizations (heart failure, cardiac, and non-cardiac). Hospitalization counts for each patient were corrected for length of follow-up time in subsequent analyses (see below).

\section{Data Analysis}

Structural Equation Modeling (SEM; with MPlus) (Muthen \& Muthen, 1998-2010) was used to determine the role of anger and hostility in predicting hospitalizations. Measures of anger and hostility at baseline were used in the following analyses. To determine whether the anger scales measured by the STAXI-II accurately capture the construct validity of anger within our sample, we entered the 6 subscales of the STAXI-II (State Anger, Trait Anger, Anger Expression In, Anger Expression Out, Anger Control In, and Anger Control Out) as indicators of Anger into a measurement model and assessed model fit. This same process was then repeated with the 7 subscales of the Cook-Medley Hostility Scale (Cynical Hostility, Hostile Attributions, Hostile Affect, Social Avoidance, Aggressive Responding and Other). The Total Hostility scale of the Cook-Medley was omitted from the analyses due to the high correlation with the other subscales (this scale was correlated with the other 5 scales at $r=.65, p<.001$ or greater, see Table 3). A Confirmatory Factor Analysis (CFA) was followed to determine the correlation between the two latent constructs (see Figure 1).

Finally, Structural Equation Models were run evaluate the possible predictive power of anger and hostility for each of the hospitalization measures: non-cardiac hospitalizations, cardiac hospitalizations (this was a composite variable that included HF hospitalizations), HF hospitalizations, and all-cause (total of cardiac and non-cardiac) hospitalizations. If the overall construct was found to significantly predict these endpoints in the SEM analysis, linear regressions were then used to determine the relationship of individual subscales to each hospitalization outcome. Covariates in all models included gender, race, income, and length of time for which follow-up data was available for that subject (i.e., length of time in the study). Smoking was not included as a covariate since it was not a significant predictor in this sample and we sought to limit number of covariates due to study sample size.

Because there were a few extreme outliers with a very large number of hospitalizations 
created by unusual non-medical reasons, hospitalizations were truncated at no more than two standard deviations above the mean. For example, one participant had over 100 hospitalizations that were not linked to any medical condition (e.g., seeking shelter and food), and therefore an artificial inflation of hospitalization data. Any missing values from the independent variables were estimated using the maximum likelihood estimation with MPlus. We used traditional SEM and linear regression methods in this study rather than Poisson regression analyses of count data, since hospitalizations were not rare events. We treat hospitalizations as a continuous variable assuming an underlying continuous scale in number of hospital stays. Poisson analyses of these data yielded results similar and not significantly different from those presented.

\section{Results}

Of the total 146 participants initially enrolled, 112 of our sample were male (76\%) and 34 female (24\%). The mean age was $57.51(\mathrm{SD}=11.42)$ years (see Table 1 for demographics). A majority of the sample were African Americans (69.9\%) and predominately lower or lower middle class.

\section{Number and Cause of Hospitalizations}

The mean length of study follow-up was 24.76 months ( $\mathrm{SD}=13.40$ months). Overall 94 participants (62.7\% of our sample) had been hospitalized at least once for any reason. Among these individuals, there were 291 cardiac-related hospitalizations (183 were heart failure related hospitalizations) accounted for by 54 participants. There were 108 non-heart failure cardiovascular-related related hospitalizations in 53 patients, and 284 hospitalizations for non-cardiac causes (non-cardiac surgeries, acute illness, injuries) in 68 patients. For allcause hospitalizations, 56 patients had 0 hospitalizations, 23 patients had 1, 18 had 2, 9 had 3,5 had 4 , and 39 had 5 or more hospitalizations, respectively. Table 2 presents a breakdown of number and cause of hospitalizations and excludes outliers. As illustrated by Table 2, a majority of non-cardiac related hospitalizations were a result of non-cardiac related chest pain (e.g., GERD), acute illness (e.g., pneumonia, bronchitis), chronic illness (e.g., COPD), undifferentiated symptoms, and other (e.g., supratherapeutic INR). For this sample, the mean number of HF related hospitalizations was 1.95 ( $\mathrm{SD}=2.93$ ), the mean number of cardiac related hospitalizations was $3.10(\mathrm{SD}=3.66)$, the mean number of non-cardiac hospitalizations was 3.02 ( $\mathrm{SD}=9.19$ ), and the mean number of all-cause hospitalizations was $3.83(\mathrm{SD}=9.40)$.

\section{Structural Equation Modeling (SEM)}

Confirmatory Factor Analysis-Table 3 presents the means and standard deviations for the observed variables that fit in the measurement models for hostility and for anger, respectively. Table 3 also includes correlations between Anger and Hostility Subscales. Analyses revealed that the latent construct of Anger was comprised of Anger ExpressionOut (Mean=14.22, SD=4.74), Anger Expression-In (Mean=15.38, SD=5.14), State Anger (Mean=16.77, SD=5.39), and Trait Anger (Mean=16.34, SD=6.14), as Anger Control-In and Anger Control-Out did not fit the hypothesized model (see Figure 1). The hypothesized model included all 6 subscales suggested by Spielberger (1999). 
The latent construct of Hostility comprised of Cynicism (Mean=7.79, SD=2.86), Hostile Attribution (Mean=4.91, SD=2.64), Hostile Affect (Mean=1.87, SD=1.31), and Aggressive Responding (Mean=4.07, $\mathrm{SD}=1.85$ ), as Social Avoidance and Other did not fit the hypothesized model and were therefore removed (see Figure 1). The Comparative Fit Index [CFI (Bentler, 1990)] of the two factor model was .99, indicating good fit. The Tucker-Lewis Index (TLI, or otherwise known as the Non-Normed Fit Index) of .98 also suggested a good fit (Hu \& Bentler, 1999). Furthermore, the Root Mean Square Error of Approximation (RMSEA) was .03 (Steiger, 2007) (Figure 1). The two constructs within the model were not significantly correlated with one another $(b=-1.6, p=.09$, S.E. Est. $=-.61)$.

Structural model-Results of these analyses revealed that the construct of Anger was not a significant predictor to any hospitalizations or death $(B=-2.15$, S.E. Est. $=-.45)$. However, the construct of Hostility did significantly predict all-cause hospitalizations $[(B=.70$, S.E. Est.=3.1) see Figure 2)]. Based on the criteria of Bentler (1990), Hu and Bentler (1999), and Steiger (2007) the model demonstrated good model fit: CFI=.95, TLI= .93, and RMSEA=. 05. The R-Squared value for Cynicism, Hostile Attribution, Hostile Affect, and Hostile Affect was $.69, .29, .16$, and .99, respectively when predicting all-cause hospitalizations, indicating relative importance to the Hostility construct. It is noteworthy, that as a covariate, gender was significant within this model, indicating a gender difference in all-cause hospitalizations.

\section{Linear Regressions}

We subsequently broke the constructs down into their observed scores, and ran linear regressions (see Tables 4-5) to determine the role of each subcomponent in hospitalizations. As with the overall models age, gender, and race were used as covariates within the regression analyses. Analyses found that Trait Anger predicted non-cardiac hospitalizations $\left(\mathrm{R}^{2}=.08, \mathrm{~B}=.12, p=.05\right.$, see Table 5), even after controlling for covariates. Additionally, Anger Expression Out significantly predicted all-cause hospitalizations $\left(\mathrm{R}^{2}=.93, \mathrm{~B}=.15, p=\right.$. 05 , see Table 4), and non-cardiac hospitalizations $\left(\mathrm{R}^{2}=.16, \mathrm{~B}=.22, p=.001\right.$, see Table 5) even when controlling for covariates. None of Hostility's other subcomponents predicted hospitalizations or death. Results did not differ when death was included as an event or when those who had died $(n=21)$ were excluded from the analyses.

\section{Discussion}

The present results indicate that Anger and Hostility each represent valid underlying psychological constructs in this HF population, and that elements of anger and hostility are both predictive of all-cause hospitalizations in patients with HF. Within this patient population, hostility and anger predicted both non-cardiac, as well as cardiac related, hospitalizations. This association of Hostility with all-cause hospitalizations is not surprising for two reasons: first, studies indicate that since there are many comorbidities in patients with HF, a significant number of recurrent hospitalizations in this group are from noncardiac causes (Krumholz, 2013; van Deursen et al., 2014); and second, there is evidence that Hostility as measured by the Cook-Medley Hostility Inventory predicts all-cause mortality, as well as cardiac-related events in patients with coronary heart disease (Barefoot 
et al., 1983; Rafanelli, Gostoli, Tully, \& Roncuzzi, 2016; Wong et al., 2014). The pattern of the association between anger/hostility study variables and hospitalizations differed between the Hostility and Anger constructs. The Hostility construct, but not the individual component scales, predicted all-cause hospitalizations even after adjusting for age, race, and gender. Conversely, Anger as a construct did not predict hospitalizations; however, several individual anger component scales were significant predictors.

Confirmatory factor analysis (CFA) indicated that the Hostility construct is comprised of Cynicism, Hostile Attribution, Aggressive Responding, and Hostile Affect. This finding is similar to results (Barefoot et al., 1989), which found that several of these component scales were significant predictors of survival in young adults followed longitudinally over 28 years. These investigators reasoned that Cynicism, Hostile Affect, and Aggressive Responding represented thought, emotion, and behavior, respectively, and therefore are the most powerful aspects of the Hostility construct. Our analyses suggest that these components are only predictive when taken together and all are essential, but they lack the needed predictive strength when examined individually. There are many reasons this might be the case, but the most likely is that 3 year hospitalizations in HF patients have a different set of determinants than does long-term survival in healthy subjects.

CFA in our sample also suggested that Anger is a latent construct comprised of Trait Anger, State Anger, Anger Expression-In, and Anger Expression-Out, but not Anger Control-In and Anger Control-Out. This construct structure is contrary to findings of several studies conducted in undergraduate student samples, which found that the Anger Control variable was an aspect of Anger as a construct (Forgays, Forgays, \& Spielberger, 1997; Fuqua et al., 1991). Therefore, we may be capturing a dimension of anger that is evident only among older individuals, individuals with a major chronic disease, and/or African American patient populations (see below). Furthermore, the present study indicates that only the individual components of Anger, rather than the entire construct, are predictive of all-cause and noncardiac hospitalizations. This is consistent with studies indicating the presence of a relationship between Anger Expression and Trait Anger and higher blood pressure levels, which is a known risk factor for HF (Schum, Jorgensen, Verhaeghen, Sauro, \& Thibodeau, 2003; Suls, Wan, \& Costa, 1995).

The lack of correlations between the individual components of anger and hostility (see Table 3), differs from findings of a prior study (Bishop \& Quah, 1998) reporting significant correlations between individual components of anger and hostility. This prior study studied a young, female, and healthy Asian sample, which contrasts with our predominantly African American, low socioeconomic status, sample of individuals with severe cardiovascular disease. Research does indicate that Cynical Hostility and Anger are predictive of cardiovascular endpoints in African Americans (e.g., Asari, 2017), and these traits appear to be expressed differently in African Americans (Johnson \& Broman, 1987). In addition to race, factors such as age, gender, and culture can also alter the expression of anger and hostility traits and their health effects (Krantz et al., 2006; Kitayama et al., 2015; Johnson \& Broman, 1987; Boisclare et al., 2014). 
The most common mechanisms proposed to account for the effects of hostility and anger on cardiovascular morbidity and mortality include increased sympathetic nervous system and/or inflammatory processes. (Kop et al., 2011; Krantz, Whittaker, \& Sheps, 2011). However, it is provocative that in this study, anger and hostility variables were predictive of all-cause hospitalizations or non-cardiac hospitalizations, rather than cardiovascular hospitalizations. These findings are consistent with studies indicating that hostility is predictive of total mortality, and not just cardiovascular mortality (Barefoot et al., 1983; Barefoot et al., 1989; Wong et al., 2014). This suggests that there is an underlying mechanism common to a variety of health problems, and not just to cardiovascular disease.

Behavioral and psychosocial variables that contribute to a variety of health problems include risky health behaviors, poor self-care, and lack of adequate social support. In this regard, evidence also indicates that Hostility is also associated with risky behaviors (Schwebel et al., 2006), poor self-care (Lee et al., 1992; Pulkki, Kivimaki, Elovainio, Viikari, \& KeltikangasJarvinen, 2003), and tends to cluster with other risk factors (Bunde \& Suls, 2006). It is therefore possible that poor self-care behaviors as physical activity, daily weighing, dietary and medication adherence, etc. (Riegel et al., 2004) may mediate associations between hostility or anger traits and increased hospitalizations in HF patients. Another possible mediator is the association between high levels of hostility and poor social support networks (Hardy \& Smith, 1988). Social support is a predictor of both hospitalizations and mortality (Luttik, Jaarsma, Moser, Sanderman \& van Veldhuisen, 2005), and poor support networks may interact with self-care and risky behaviors to increase hospitalization risk. However, prior research has not specifically examined these factors with respect to their possible role as mediators of relationships between hostility traits and hospitalizations, and further research is needed to address the issue of mechanisms. Although the larger BETRHEART study included measures of self-care and social support, relationships of Hostility to the multiple mediating mechanisms contributing to hospitalizations are likely complex, and their examination is beyond the scope of this article.

\section{Clinical Implications}

Prospective studies examining the role of anger and hostility in cardiovascular disease suggest that these traits play a role in disease etiology and in the development of atherosclerosis. Evidence further indicates that hostility is related to poor health habits (Pulkki et al., 2003), which may, in turn, increase risk for morbidity and mortality from a variety of disorders in seriously ill patients with chronic heart failure. Results of this study indicate that hostility traits have wider consequences for the burden on the health care system and perhaps for overall health care costs. Therefore, the presence of hostility traits in chronically ill patients with moderate to advanced HF may help to identify individuals who should be targeted for screening and interventions that may reduce hospitalizations, such as case management, attention to improved doctor-patient communication, patient education, and collaborative care (Bradley et al., 2013).

\section{Study Limitations}

There are several study limitations that should be noted. First, the present study did not test possible mediating mechanisms such as health risk behavior and social support, which were 
beyond the scope of this paper. Results of this study may also not be generalizable to more representative population of patients with heart failure since the present sample was majority African American, of lower socioeconomic status, and had relatively severe heart failure. However, the study does provide information about psychological determinants of heart failure in an under-represented ethnic minority in need of further study. In AfricanAmericans, the causes of heart failure are more likely to be non-ischemic (i.e., not due to coronary artery disease), as opposed to ischemic (due to coronary artery disease), and are more likely to develop heart failure at younger ages (Sharma, Colvin-Adams, \& Yancy, 2014). For this and other reasons, an additional result of this is that our study population was somewhat younger than one would find in the typical sample of patients with ischemic heart failure.

Another issue that should be noted is that although primary causes of hospital admissions were verified in patients' hospital records, problems leading to admission are often causally interrelated and highly comorbid with one another. Therefore, identifying a primary cause of hospitalization may be somewhat arbitrary, and conclusions regarding distinctions between heart failure, cardiac, and non-cardiac causes of re-admission should be evaluated with this in mind. However, hospitalizations, regardless of primary causes, are a major cause of health care expenditures (Alharethi et al., 2013; Dunlay et al., 2011; Jencks et al., 2009; Krumholz, 2013), and it is important to understand their determinants, and arguably an important strength of the study. Lack of power is another limitation that must be taken into consideration. Although there is no consensus within the literature in regards to completing a power analysis for SEM, experts do suggest that there should be approximately 10 participants for every observed variable (Kline, 2011). By this standard, the current analyses conform to these particular guidelines.

In sum, although the research on hostility and anger has largely focused on cardiovascular disease risk, future research would benefit from further examination of general health impairing behaviors that are associated with hostility and anger, and that might contribute to poorer health outcomes and increased risk of re-hospitalization in vulnerable individuals with serious chronic diseases such as HF. Indeed, understanding of the behavioral determinants of multi-morbidity is seen as an emerging area of bio-behavioral research (Suls, Green, \& Davidson, 2016). Screening for hostility and anger traits in heart failure patients may help identify individuals at higher risk for hospitalization. In addition, interventions to reduce these characteristics may contribute a reduction in re-hospitalization risk in HF and contribute to reducing the burden and cost on the health care system.

\section{Acknowledgments}

This work was supported by National Heart Lung and Blood Institute grant RO1-HL085730. The opinions and assertions expressed herein are those of the authors and are not to be construed as representing the views of Uniformed Services University or the US government.

\section{References}

Alharethi R, Rasmusson K, Budge D, Benuzillo JG, Kfoury AG. Impact of chronic comorbidities on heart failure 30 days readmission. J Card Fail. 2013; 19(8):35.doi: 10.1016/j.cardfail.2013.06.116 
Angerer P, Siebert U, Kothny W, Muhlbauer D, Mudra H, Schacky C. Impact of scial support, cynical hostility and anger expression on progression of coronary atherosclerosis. Journal of American College of Cardiology. 2000; 36:1781-1788.

Asari S. Hostility, Anger, and Cardiovascular Mortality Among Blacks and Whites. Research in Cardiovascular Medicine. 2017; 6(1):e34029.doi: 10.5812/cardiovascmed.34029

Barefoot JC, Dahlstrom WG, Williams RB Jr. Hostility, CHD incidence, and total mortality: A 25-year follow-up study of 255 physicians. Psychosom Med. 1983; 45(1):59-63. [PubMed: 6844529]

Barefoot JC, Dodge KA, Peterson BL, Dahlstrom WG, Williams RB Jr. The Cook-Medley hostility scale: item content and ability to predict survival. Psychosom Med. 1989; 51(1):46-57. [PubMed: 2928460]

Bentler PM. Comparative fit indexes in structural models. Psychol Bull. 1990; 107(2):238-246. DOI: 10.1037/0033-2909.107.2.238 [PubMed: 2320703]

Bishop GD, Quah S. Reliability and validity of measures of anger/hostility in Singapore: Cook \& Medley HO scale, STAXI, and Buss-Durkee Hostility Inventory. Pers Individ Dif. 1998; 24(6):867_ 878.

Black D, Zimmerman M, Coryell WH. Cigarette smoking and psychiatric disorder in a community sample. Annuals of Clinical Psychiatry. 1999; 11

Boisclair Demarble J, Moskowitz DS, Tardif JC, D'Antono B. The relation between hostility and concurrent levels of inflammation is sex, age, and measure dependent. J Psychosom Res. 2014; 76(5):384-93. DOI: 10.1016/j.jpsychores.2014.02.010 [PubMed: 24745780]

Bradley EH, Curry L, Horwitz LI, Sipsma H, Wang Y, Walsh MN, Goldman D, White N, Pina IL, Krumholz HM. Hospital strategies associated with 30- day readmission rates for patients with heart failure. Circulation: Cardiovascular Quality and Outcomes. 2013; 06:444-450. DOI: 10.1161/CIRCOUTCOMES.111.000101

Buckley T, Soo Hoo SY, Fethney J, Shaw E, Hanson PS, Tofler GH. T riggering of acute coronary occlusion by episodes of anger. Cardiovascular Care. 2015; doi: 10.1177/2048872615568969

Bunde J, Suls J. A quantitative analysis of the relationship between the Cook-Medley hostility scale and traditional coronary artery disease risk factors. Health Psychology. 2006; 25(4):493-500. [PubMed: 16846324]

Chaput LA, Adams SH, Simon JA, Blumenthal RS, Vittinghoff E, Lin F, Loh E, Matthews KA. Hostility predicts recurrent events among postmenopausal women with coronary heart disease. Am J Epidemiol. 2002; 156(12):1092-1099. [PubMed: 12480653]

Chida Y, Steptoe A. The association of anger and hostility with future coronary heart disease. J Am Coll Cardiol. 2009; 53(11):936-946. [PubMed: 19281923]

Cohen S, Wills TA. Stress, social support, and the buffering hypothesis. Psychological bulletin. 1985; 98:310-57. [PubMed: 3901065]

Cook WW, Medley DM. Proposed hostility and pharisaic-virtue scales for the MMPI. Journal of Applied Psychology. 1954; 38:414-418.

Costa PT Jr, Zonderman AB, McCrae RR, Williams RB Jr. Cynicism and paranoid alienation in the Cook and Medley HO Scale. Psychosom Med. 1986; 48(3):283-285. DOI: 10.1097/00006842-198603000-00014 [PubMed: 3704090]

Denollet J, Pedersen SS. Anger, depression and anxiety in cardiac patients: The complexity of individual differences in psychological risk. J Am Coll Cardiol. 2009; 53(11):947-949. DOI: 10.1016/j.jacc.2008.12.006 [PubMed: 19281924]

Dunlay SM, Shah ND, Shi Q, Morlan B, VanHouten H, Long KH, Roger VL. Lifetime costs of medical care after heart failure diagnosis. Circulation: Cardiovascular Quality and Outcomes. 2011; 4:68-75. DOI: 10.1161/CIRCOUTCOMES.110.957225 [PubMed: 21139091]

Endrighi R, Waters AJ, Gottlieb SS, Harris KM, Wawrzyniak A, Bekkouche NS, Li Y, Kop WJ, Krantz DS. Psychological stress and short-term hospitalizations or death in patients with heart failure. Heart. 2016; 102(22)doi: 10.1136/heartjnl-2015-309154

Etzler SL, Rohrmann S, Brandt H. Validation of the STAXI-2: A study with prison inmates. Psychological Test and Assessment Modeling. 2014; 56(2):178-194.

Forgays DG, Forgays DK, Spielberger CD. Factor structure of the state-trait anger expression inventory. J Pers Assess. 1997; 69(3):497-507. [PubMed: 9501480] 
Fuqua DR, Leonard E, Masters MA, Smith RJ, Campbell JL, Fischer PC. A structural analysis of the state-trait anger expression inventory. Educational and Psychological Measurement. 1991; 51:439_ 446.

Gabbay FH, Krantz DS, Kop WJ, Hedges SM, Klein J, Gottdiener JS, Rozanski A. Triggers of myocardial ischemia during daily life in patients with coronary artery disease: physical and mental activities, anger and smoking. Journal of American College of Cardiology. 1996; 27(3):585-592.

Green CP, Porter CB, Bresnahan DR, Spertus JA. Development and evaluation of the KCCQ: A new health status measure for heart failure. Journal of the American College of Cardiology. 2000; 35:1245-55. [PubMed: 10758967]

Hardy JD, Smith TW. Cynical hostility and vulnerability to disease: social support, life stress, and physiological response to conflict. Health Psychology. 1988; 7(5):447-459. [PubMed: 3215156]

$\mathrm{Hu}$ L, Bentler PM. Cutoff criteria for fit indexes in covariance structure analysis: Conventional criteria versus new alternatives. Structural Equation Modeling. 1999; 6:1-55.

Jencks SF, Williams MV, Coleman EA. Rehospitalizations among patients in the medicare fee-forservice program. N Engl J Med. 2009; 360:1418-1428. DOI: 10.1056/NEJMsa0803563 [PubMed: 19339721]

Jenner RC, Strodl ES, Schweitzer RD. Anger and depression predict hospital use among chronic heart failure patients. Aust Health Rev. 2009; 33(4):541-548. [PubMed: 20166902]

Johnson EH, Broman CL. The relationship of anger expression to health problems among black americans in a national survey. J Behav Med. 1987; 10(2):103-116. [PubMed: 3612773]

Kitayama S, Park J, Boylan JM, Miyamoto Y, Levine CS, Markus HR, Karasawa M, Coe CL, Kawakami N, Love GD, Ryff CD. Expression of anger and ill health in two cultures: an examination of inflammation and cardiovascular risk. Psychological Science. 2015; 26(2):211-20. [PubMed: 25564521]

Kline, RB. Principles and Practice of Structual Equation Modeling. New York, NY: The Guilford Press; 2011.

Kop WJ, Synowski SJ, Gottlieb SS. Depression in heart failure: Biobehavioral mechanisms. Heart Fail Clin. 2011; 7(1):23-28. DOI: 10.1016/j.hfc.2010.08.011 [PubMed: 21109205]

Krantz DS, Olson MB, Francis JL, Phankao C, Bairey MCN, Sopko G, Vido DA, Shaw LJ, Sheps DS, Pepine CJ, Matthews KA. Anger, hostility, and cardiac symptoms in women with suspected coronary artery disease: the Women's Ischemia Syndrome Evaluation (WISE) Study. Journal of Women's Health. 2006; 15(10):1214-1223.

Krantz, DS., Whittaker, KS., Sheps, DS. Psychosocial risk factors for Coronary Artery Disease: Pathophysiologic Mechanisms. In: Allan, R., Fisher, J., editors. Heart and Mind: Evolution of Cardiac Psychology. Washington DC: APA Press; 2011.

Krumholz HM. Post-hospital syndrome- An acquired, transient condition of generalized risk. New England Journal of Medicine. 2013; 368:100-102. DOI: 10.1056/NEJMp1212324 [PubMed: 23301730]

Kucharska-Newton AM, Williams JE, Chang PP, Stearns SC, Sueta CA, Blecker SB, Mosley TH. Anger proness, gender, and the risk of heart-failure. J Card Fail. 2014; 20(12):1020-1026. DOI: 10.1016/j.cardfail.2014.09.010 [PubMed: 25284390]

Lee D, Mendes de Leon CF, Jenkins DC, Croog SH, Levine S, Sudilovsky A. Relation of hostility to medication adherence, symptom complaints, and blood pressure reduction in a clinical field trial of antihypertensive medication. J Psychosom Res. 1992; 36(2):181-190. [PubMed: 1560429]

Levy D, Kenchaiah S, Larson MG, Benjamin EJ, Kupka MJ, HO KK, Murabito JM, Vasan RS. Longterm trends in the incidence of and survival with heart failure. New England Journal of Medicine. 2002; 347(18):1397-1402. [PubMed: 12409541]

Lloyd-Jones D, Adams RJ, Brown TM, Carnethon M, Dai S, De Simone G, Ferguson TB, Ford E, Furie K, Gillespie C, Go A, Greenlund K, Haase N, Hailpern S, Ho PM, Howard V, Kissela B, Kittner S, Lackland D, Lisabeth L, Marelli A, McDermott MM, Meigs J, Mozaffarian D, Mussolino M, Nichol G, Roger VL, Rosamond W, Sacco R, Sorlie P, Thom T, WasserthielSmoller S, Wong ND, Wylie-Rosett J. Subcommittee, A. H. A. S. C. a. S. S. Heart disease and stroke statistics--2010 update: a report from the American Heart Association. Circulation. 2010; 121(7):46-215. DOI: 10.1161/CIRCULATIONAHA.109.192667 
Luttik ML, Jaarsma T, Moser DK, Sanderman R, van Veldhuisen DJ. The importance and impact of social support on outcomes in patients with heart failure: An overview of the literature. Journal of Cardiovascular Nursing. 2005; 20(3):162-169. [PubMed: 15870586]

McDermott MM, Schmitt B, Wallner E. Impact of medication nonadherence on coronary heart disease outcomes: A critical review. Arch Intern Med. 1997; 157(17):1921-1929. DOI: 10.1001/archinte. 1997.00440380023002 [PubMed: 9308504]

Miller GE, Freedland KE, Carney RM, Stetler CA, Banks WA. Cynical hostility, depressive symptoms, and the expression of inflammatory risk markers for coronary heart disease. J Behav Med. 2003; 26(6):501-515. [PubMed: 14677209]

Mittleman MA, Maclure M, Sherwood JB, Mulry RP, Tofler GH, Jacobs SC, Friedman R, Benson H, Muller JE. Triggering of acute myocardial infarction onset by episodes of anger. Circulation. 1995; 92:1720-1725. [PubMed: 7671353]

National Center for Chronic Disease Prevention and Health Promotion, D. f. H. D. a. S. P. Heart Failure Death Rates Among Adults Aged 65 years and Older by State, 2006. Washington, D.C: Center for Disease Control; 2010.

Pulkki L, Kivimaki M, Elovainio M, Viikari J, Keltikangas-Jarvinen L. Contribution of socioeconomic status to the association between hostility and cardiovascular risk behaviors: A prospective cohort study. Am J Epidemiol. 2003; 158(8):736-742. https://doi.org/10.1093/aje/kwg204. [PubMed: 14561662]

Rafanelli C, Gostoli S, Tully PJ, Roncuzzi R. Hostility and the clinical course of outpatients with congestive heart failure. Psychological Health. 2016; 31(2):228-238. DOI: 10.1080/08870446.2015.1095299

Riegel B, Carlson B, Moser DK, Sebern M, Hicks FD. Psychometric testing of the self-care of heart failure index. Journal of cardiac failure. 2004; 10:350-60. [PubMed: 15309704]

Rutledge T, Reis V, Linke S, Greenberg BH, Millis PJ. Depression in heart failure: A meta-analytic review of prevalence, intervention effects, and associations with clinical outcomes. J Am Coll Cardiol. 2006; 48(8):1527-1537. DOI: 10.1016/j.jacc.2006.06.055 [PubMed: 17045884]

Schum JL, Jorgensen RS, Verhaeghen P, Sauro M, Thibodeau R. Trait anger, anger expression, and ambulatory blood pressure: A meta-analytic review. J Behav Med. 2003; 26(5):395-415. [PubMed: 14593850]

Schwebel DC, Severson J, Karlene KB, Matthew R. Individual difference factors in risky driving: The roles of anger/hostility, conscientiousness, and sensation-seeking. Accident Analysis \& Prevention. 2006; 38(4):801-810. [PubMed: 16527223]

Sharma A, Colvin-Adams M, Yancy CW. Heart failure in African Americans: Disparities can be overcome. Cleveland Clinic Journal of Medicine. 2014; 81(5):301-311. DOI: 10.3949/ccjm.81a. 13045 [PubMed: 24789589]

Smith TW, Frohm KD. What's so unhealthy about hostility? Construct validity and psychosocial correlates of the Cook and Medley Ho scale. Health Psychol. 1985; 4(6):503-520. [PubMed: 3830702]

Spielberger. State-trait anger expression inventory-2. Odessa, FL: Psychological Assessment Resources, Inc.; 1999.

Spielberger, Jacobs, G., Russell, SF., Crane, RS. Assessment of anger: The state-trait anger scale. In: Butcher, JN., Spielberger, CD., editors. Advances in Personality Assessment. Vol. 2. Hillsdale, NJ: Lawrence Erlbaum Associates, Inc.; 1983.

Steiger JH. Understanding the limitations of global fit assessment in structural equation modeling. Pers Individ Dif. 2007; 42(5):893-898. DOI: 10.1016/j.paid.2006.09.017

Suls J, Bunde J. Anger, anxiety, and depression as risk factors for cardiovascular disease: the problems and implications of overlapping affective dispositions. Psychol Bull. 2005; 131(2):260-300. DOI: 10.1037/0033-2909.131.2.260 [PubMed: 15740422]

Suls J, Green PA, Davidson KW. A Biobehavioral Framework to Address the Emerging Challenge of Multimorbidity. Psychosom Med. 2016 Apr; 78(3):281-9. DOI: 10.1097/PSY.0000000000000294 [PubMed: 26867072]

Suls J, Wan CK, Costa PT. Relationship of trait anger to resting blood pressure: A meta-analysis. Health Psychology. 1995; 14:444-456. [PubMed: 7498116] 
van Deursen VM, Urso R, Laroche C, Damman K, Dahlstrom U, Tavazzi L, Maggioni AP, Voors AA. Co-morbidities in patients with heart failure: An analysis of the European Heart Failure Pilot Survey. Eur J Heart Fail. 2014; 16(1):103-111. DOI: 10.1002/ejhf.30 [PubMed: 24453099]

Wong JM, Na B, Regan MC, Whooley MA. Hostility, health behaviors, and risk of recurrent events in patients with stable coronary heart disease: Findings from the heart and soul study. Journal of American Heart Association. 2013; 2doi: 10.1161/JAHA.113.000052

Wong JM, Sin NL, Whooley MA. A comparison of cook-medley hostility subscales and mortality in patients with coronary heart disease: Data from the heart and soul study. Psychosom Med. 2014; 76(4):311-317. DOI: 10.1097/PSY.0000000000000059 [PubMed: 24804880] 


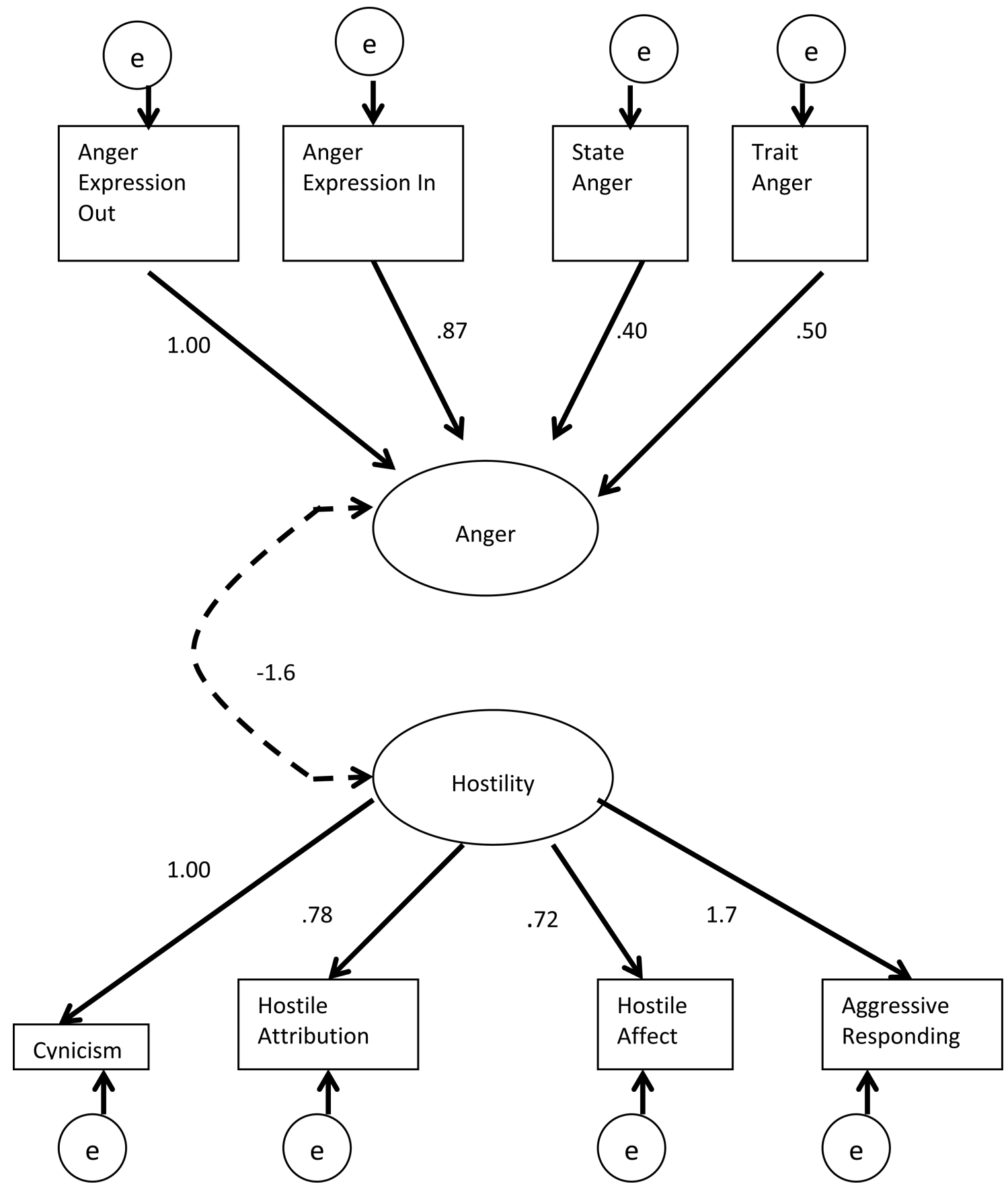

Figure 1. Confirmatory Factor Analysis of Anger and Hostility

Anger and Hostility are the latent variables and boxes represent all of the observed variables. The path loadings presented above are non-standardized estimates (B) and the solid lines represent significant paths at $p<.05$. Fit indices for this model are: CFI $=0.99$, TLI $=0.98$, and RMSEA $=0.03$. The dashed line represents a non-significant path $(p=.09)$. 


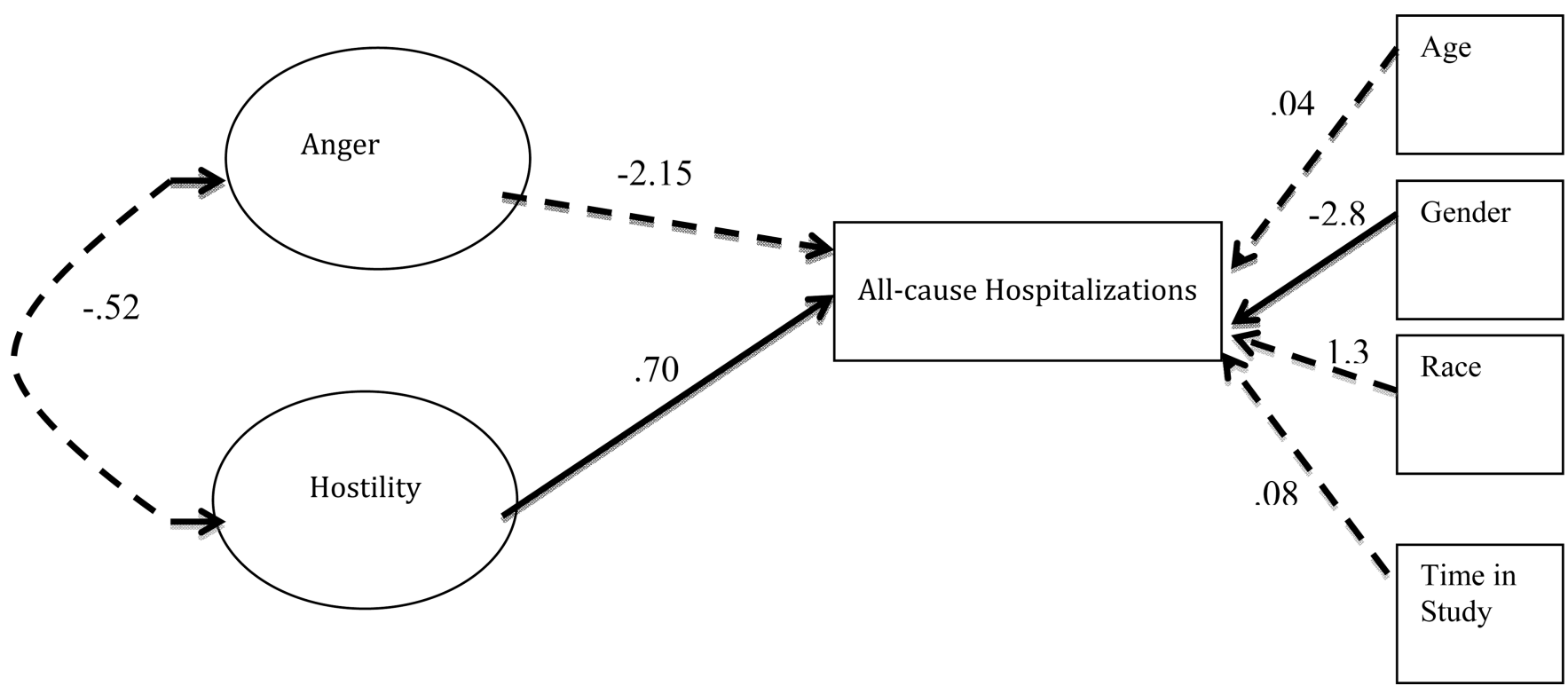

Figure 2. Structural Model: Hostility Predicting All-Cause Hospitalizations

Path loadings presented are non-standardized estimates (B). The solid lines represent significant paths at $p<.05$ and dashed lines represent all non-significant paths. $\mathrm{CFI}=.96$, $\mathrm{TLI}=.94$, and RMSEA $=.05$. 


\section{Table 1}

Sample Demographic and Medical Characteristics, mean (s.d.) or N(\%)

\begin{tabular}{lcc}
\hline Variable & $\begin{array}{c}\text { Full Sample } \\
\text { N=146 }\end{array}$ & Mean or \% \\
\hline Male Gender & & $112(76 \%)$ \\
Age (years) & $57.51(1.42)$ \\
Race & African American & $102(69.9 \%)$ \\
& Caucasian & $43(29.5 \%)$ \\
& Other & $1(0.7 \%)$ \\
Household Income & $<\$ 15,000$ & $51(34.9 \%)$ \\
& $\$ 15-30,000$ & $39(26.7 \%)$ \\
& $\$ 30-70,000$ & $43(29.5 \%)$ \\
History of Hypertension & $>\$ 70,000$ & $13(8.9 \%)$ \\
Creatinine (mg/dl) & & $116(77 \%)$ \\
Ejection fraction (\%) & & $1.38(.71)$ \\
History of Smoking (\% yes)| & & $23.14(7.48)$ \\
Mean time in the Study (months) & & $103(70.5 \%)$ \\
\hline
\end{tabular}




\section{Table 2}

Number of Cardiac, Non-Cardiac, and All-Cause Hospitalizations *

\begin{tabular}{llc}
\hline Cause & Admitting diagnosis & N \\
\hline \multirow{3}{*}{ Cardiac } & Heart Failure & 183 \\
& Angina & 35 \\
& ICD related & 32 \\
& Hypo/hypertension & 9 \\
& Myocardial Infarction & 7 \\
& Shortness of breath & 6 \\
& Stroke & 5 \\
& Other & 14 \\
& Total N, cardiac hospitalizations & 291 \\
Non-cardiac & Non-cardiac chest pain & 58 \\
& Psychiatric & 10 \\
& Injury (e.g., broken arm) & 14 \\
& Acute Illness (e.g., pneumonia) & 56 \\
& Chronic Illness (e.g., cancer, COPD) & 54 \\
& Surgery (e.g., back, knee) & 13 \\
& Undifferentiated Symptoms & 40 \\
& Other (e.g., INR, sleep study) & 39 \\
& Total $N$, non-cardiac Hospitalizations & 284 \\
\hline & & \\
& & 575
\end{tabular}

All-Cause $\quad$ Total N, al-cause hospitalizations $\quad 575$

* Note: Hospitalization numbers represent actual full non-truncated data. Number of hospitalizations exceeds the number of patients because some participants had multiple hospitalizations, including both cardiac and noncardiac hospitalizations. N=107 patients had at least one cardiac hospitalization, and $\mathrm{N}=68$ participants had at least one non-cardiac hospitalization. Data from one outlier participant with $>100$ hospitalizations were excluded from these totals. 


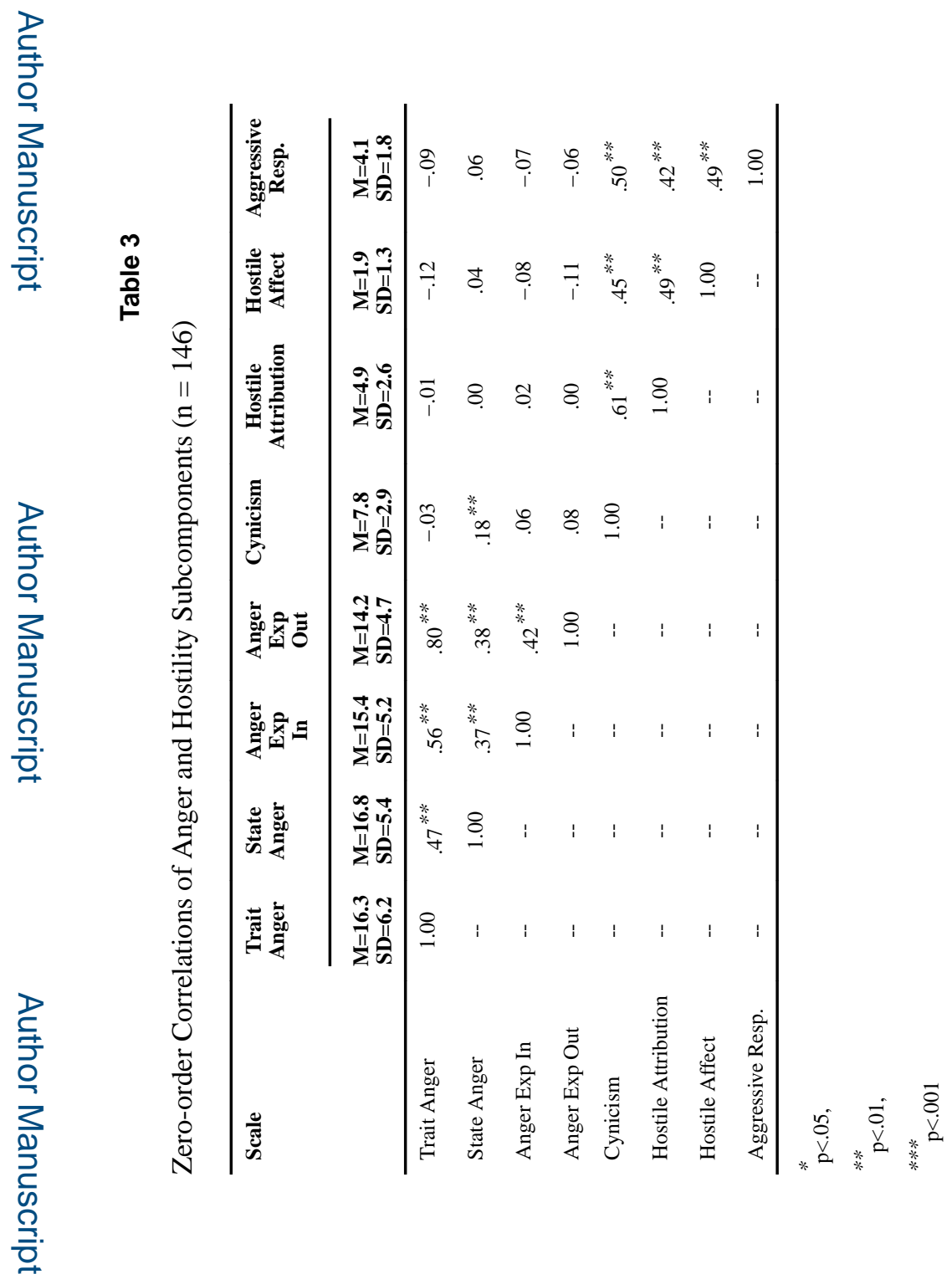

Health Psychol. Author manuscript; available in PMC 2018 September 01. 
Table 4

Anger and Hostility Subcomponents Predicting All-Cause Hospitalizations

\begin{tabular}{lccc}
\hline & B & CI 95\% & $p$ \\
\hline $\begin{array}{l}\text { Step One } \\
\text { Covariates }\end{array}$ & \multicolumn{3}{c}{ Block Significant } \\
\hline $\begin{array}{l}\text { Step Two } \\
\text { Covariates }\end{array}$ & & & \\
State Anger & .04 & $-.09-.17$ & .54 \\
Trait Anger & .10 & $-.02-.21$ & .09 \\
Anger Exp Out & $.15^{*}$ & $.01-.30$ & .04 \\
Anger Exp In & .07 & $-.07-.20$ & .32 \\
Cynicism & .07 & $-.19-.33$ & .61 \\
Hostile Attribution & .05 & $-.24-.34$ & .74 \\
Hostile Affect & .11 & $-.45-.67$ & .69 \\
Aggressive Responding & -.05 & $-.45-.35$ & .79 \\
\hline$*$ & & & \\
$p^{<.05}$ & & &
\end{tabular}


Table 5

Anger and Hostility Subcomponents Predicting Non-cardiac Hospitalizations

\begin{tabular}{lccc}
\hline & B & CI 95\% & $p$ \\
\hline $\begin{array}{l}\text { Step One } \\
\text { Covariates }\end{array}$ & \multicolumn{3}{c}{ Block Significant } \\
\hline $\begin{array}{l}\text { Step Two } \\
\text { Covariates }\end{array}$ & & & \\
State Anger & .08 & $-.04-.19$ & .21 \\
Trait Anger & $.12^{*}$ & $.04-.21$ & .04 \\
Anger Exp Out & $.22^{* * *}$ & $.10-.35$ & .001 \\
Anger Exp In & .02 & $-.11-.15$ & .74 \\
Cynicism & .04 & $-.19-.27$ & .72 \\
Hostile Attribution & -.08 & $-.35-.18$ & .53 \\
Hostile Affect & .08 & $-.48-.64$ & .78 \\
Aggressive Responding & -.20 & $-.56-.17$ & .28 \\
\hline
\end{tabular}

* $p<.05$,

*** $p<.01$,

$* * * 0001$ 